\title{
Emergency medicine for frogs
}

\section{With chytrid fungus rapidly spreading around the world, researchers are testing an extreme approach to saving endangered amphibian populations. Naomi Lubick reports from a rescue site.}

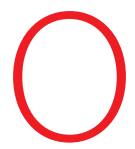

$n$ a mid-April afternoon with rain threatening, Jaime Bosch clambered down the carbonate cliffs of northern Mallorca to a pond overlooking the Mediterranean Sea. After removing his shoes and wading into the shallow pond, Bosch quickly netted 30 wriggling tadpoles and dropped them into a bag filled with water. He gently grabbed one in plastic-gloved hands, swabbed its mouth with a cotton-tipped stick, and returned the tadpole to the pond. The important information was in the DNA captured on the end of the stick.

Bosch, an evolutionary biologist at Spain's National Museum of Natural History in Madrid, and his colleagues had conducted a back-breaking experiment in 2009 to try to rid this particular pond of the chytrid fungus Batrachochytrium dendrobatidis. The fungus causes a disease called chytridiomycosis that has wiped out amphibian populations around the world. Given that history, Bosch and his team resorted to extreme measures to save the frogs on Mallorca. At this small pond, the researchers removed all the resident tadpoles during the spring and summer, treated them with an antifungal medication and returned them to the water after cleaning the pond.

When Bosch returned to the site this spring, he brought his swabbing kit to see whether the frogs were free of the fungus. He hopes that results from the experiment in Mallorca can help other scientists, who are testing similar approaches in Switzerland and California.

These and other frog researchers are closely watching the work in Mallorca because the species in the pond, the midwife toad, makes this an important test case. "Midwife toads are a sentinel species because they are so susceptible to chytrid," says Matthew Fisher, an epidemiologist at Imperial College London. Fisher heads a consortium called RACE (Risk Assessment of Chytridiomycosis to European amphibian biodiversity), which is working with Bosch. Funded by the European Union's Biodiversa research project, RACE brings together specialists such as mycologists and herpetologists to find ways to control the spread of chytrid fungus across Europe.

When Bosch's team evacuated the Mallorcan tadpoles last summer, its goal was to completely eradicate the fungus, which gained a foothold on the island about 20 years ago when frogs were imported to help boost a native species.

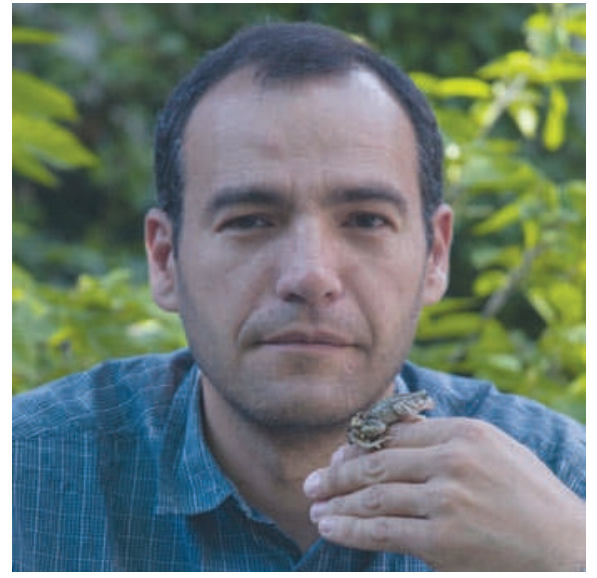

Jaime Bosch is seeking to save frogs in Europe.

"Only four populations are infected, which is why we need to take action very quickly on the island," says Bosch.

The local government agreed and pitched in, donating employees' time and funding. Some of that money covers the tests to detect fungal DNA on the tadpoles. More funding comes from the Spanish National Research Council (CSIS) and from the regional government of Madrid - which has also spent about $€ 75,000$ (US\$90,000) on a small breeding centre for two endangered frog populations in Spain's Peñalara Nature Reserve, the site of the first European outbreak of chytridiomycosis in 1997.

Last year, several scientists - including researchers from the Zoological Society of London (ZSL) and others affiliated with RACE evacuated more than 2,000 tadpoles from the Mallorcan pond, which is near the coast, west of Pollença. In four trips between late March and early August, the team carried hundreds of tadpoles at a time in well-cleaned, 2-litre bottles, filled with pond water and rigged with

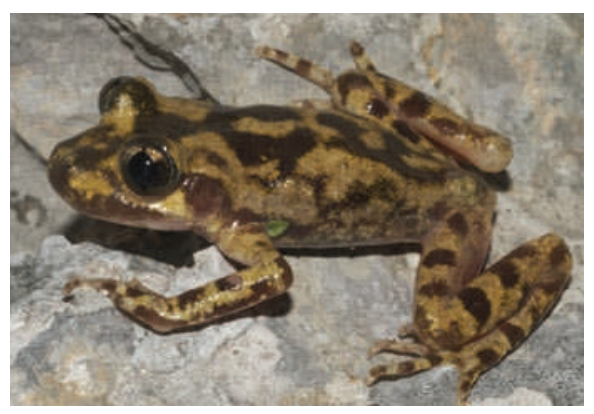

Fungal attacks threaten Mallorcan midwife toads. aquaria air pumps to get oxygen to the tadpoles during the three-hour hike out to the nearest road. The researchers then drove for several hours to a lab facility at Marineland, a dolphin tourist attraction across the island. There, the tadpoles completed a week-long regimen of daily 5-minute baths in itraconazole, an antifungal medicine, and were placed in glass aquaria for up to seven months.

Meanwhile, Bosch returned to the pond several times, to attempt to dry it out, because it is suspected that chytrid fungus needs moisture to survive. Eventually, he emptied the pond as much as he could with a bucket, and left it to dry in the hot Mallorcan summer. When the pond refilled with rain in the autumn, Bosch's team airlifted the tadpoles across the island to their home, with the hope that they would survive in the now-clean pond.

\section{Sweet sounds}

Signs were good when Bosch arrived back at the pond in April and heard faint, bell-like pings. Tracking the sound, he raced up a jagged cliff and found two healthy-looking adults, one of which had several eggs attached to its posterior. Male midwife toads carry the fertilized eggs and normally spend their days away from the pond, which makes them difficult to find, says Bosch. This male frog would soon be returning to the water to release the eggs.

Adult midwife toads are particularly vulnerable to the chytrid fungus because it attaches to keratin, which covers the adults but only the mouths of tadpoles. So finding the adults near the pond lifted Bosch's hopes, as did the hundreds of tadpoles swimming in the water.

Bosch chose Mallorca as a test site partly because the dry environment and the widely separated amphibian populations slow the spread of the fungus. That provides researchers with a chance to wipe out the pathogen, says Bosch. By contrast, it would be out of the question to eliminate the fungus from rainforest communities, such as in Central America, where water is plentiful and the fungus is widespread ${ }^{1}$.

In places where complete eradication is impractical, researchers are hoping to take a modified approach, which relies on the fact that some populations of frogs survive chytrid attack. Vance Vredenburg, a biologist at San Francisco State University in California, is searching for such populations in the Sierra Nevada. The mountain yellow-legged frog in this range is 


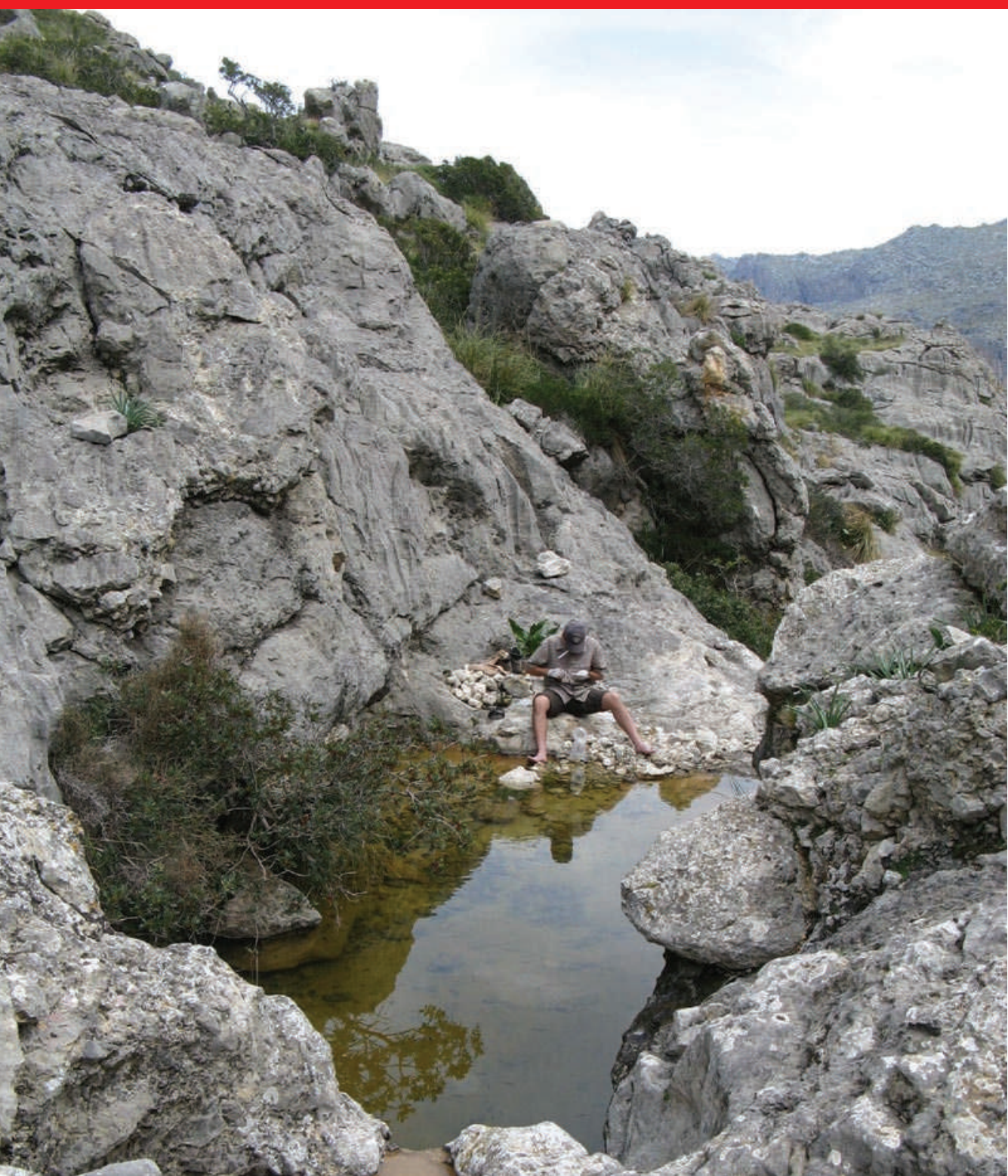

Researchers drained this remote Mallorcan pond to try to save midwife toads from chytridiomycosis.

one of the most endangered amphibians in the United States and has been hit by many chytridiomycosis outbreaks over the past decade. By analysing how the frogs responded to those infections, Vredenburg and his colleagues have developed a model that can help to identify the populations that are most at risk and which might benefit from limited intervention ${ }^{2,3}$.

Vredenburg is now adapting Bosch's technique to try to protect communities by treating some individuals. This spring, his group started capturing frogs in cages in the field, washing them in 5-minute antifungal bath each day for a week and then releasing them.

In late April, Bosch received the results from colleagues at the ZSL who had completed the analyses on the tadpole swabs taken in Mallorca. Every sample came back positive for B. dendrobatidis, which means that all the tadpoles in the pond probably carry the fungus, says Bosch. But the number of spores detected on each swab was far smaller than the number seen in tests the previous year, suggesting a lower level of infection.
Even so, the news stunned Bosch and his colleagues, who are struggling to understand how the pathogen survived in the pond at all. Jon Bielby, an ecologist at the ZSL's Institute of Zoology, who assisted last year in carrying tadpoles out, wonders whether the froglets - a stage between tadpole and adult that temporarily leaves the pond - picked up the fungus elsewhere and brought it back. Other RACE researchers have floated the idea that the fungus may have a life stage outside water. "But the honest answer is we don't know," says Bielby.

\section{Reduction not eradication}

The results on Mallorca, although disappointing, are valuable for other researchers trying to combat outbreaks of $B$. dendrobatidis $(B d)$, says Benedikt Schmidt, coordinator for amphibian and reptile conservation with the Swiss frogprotection group KARCH, based in Neuchâtel. "It means that we should focus on reducing prevalence rather than trying to eradicate $B d$ from our ponds," he says ${ }^{4}$.

Schmidt and his colleagues hope to use a variation of Bosch's technique to bolster local populations infected by the fungus in Switzerland. Working with graduate student Corina Geiger at the University of Zurich, Schmidt will pull some frogs from three ponds, treat them, and reintroduce them. They will compare those ponds with two untreated control populations. This treatment approach may become a tool to help frogs survive if the chytrid situation in Switzerland and other sites across Europe worsens, he says.

Schmidt is also focusing on other threats to frog populations, the biggest of which may be the loss or degradation of habitat. Schmidt worries that human-initiated changes to the landscape, from farming practices to creeping urbanization, are stressing amphibian populations and may be making them more vulnerable to chytrid fungus.

Schmidt and others say there is still much unknown about how chytrid affects frogs. Researchers with the RACE project and on Vredenburg's team are looking into the genetics of the fungus, trying to determine whether the infectious strains vary every year, perhaps like the flu strains that infect humans. Biologists are also trying to pinpoint frogs' molecular responses to the fungus - which genes get turned on, and which proteins are produced in response to the infection.

Although disappointed by his first test in Mallorca, Bosch remains undeterred. The reduced severity of infection may help the frogs survive in the pond, he says. And his team may try another round of antifungal baths this summer, perhaps treating the difficult-to-locate adult frogs as well as the tadpoles.

Bosch also started up fieldwork in Portugal and Hungary earlier this spring, searching for more amphibian populations infected with chytrid fungus. He is hoping to modify the Mallorcan method to treat midwife toad populations first in Peñalara, and then elsewhere in Spain as well as in Eastern Europe.

Bosch's first work with frogs was studying their communication and mating habits. His iPhone rings with the calls of six different frog species that he recorded, and he wishes he could resume his research on sexual behaviour. But for the past ten years, Bosch has spent his days working to preserve frog populations before they disappear. "It's nicer," he says, "to work with live animals."

Naomi Lubick is a freelance writer based in Zurich, Switzerland.

1. Lips, K. R. et al. Proc. Natl Acad. Sci. USA 103, 3165-3170 (2006).

2. Vredenburg, V. T., Knapp, R. A., Tunstall, T. S. \& Briggs, C. J. Proc. Natl Acad. Sci. USA 107, 9689-9694 (2010).

3. Briggs, C. J., Knapp, R. A. \& Vredenburg, V. T. Proc. Natl Acad. Sci. USA 107, 9695-9700 (2010).

4. Tobler, U. \& Schmidt, B. PLoS ONE 5, e10927 (2010). 